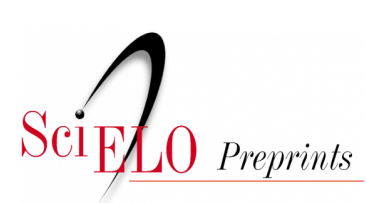

Situação: O preprint não foi submetido para publicação

\title{
PRODUZINDO A SUBALTERNIDADE: AS MERENDEIRAS NOS DOCUMENTOS E INICIATIVAS DA GESTÃO FEDERAL DO PNAE
}

\author{
Mariana Belloni Melgaço, Rodrigo Matos-de-Souza
}

https://doi.org/10.1590/SciELOPreprints.2278

Este preprint foi submetido sob as seguintes condições:

- Os autores declaram que estão cientes que são os únicos responsáveis pelo conteúdo do preprint e que o depósito no SciELO Preprints não significa nenhum compromisso de parte do SciELO, exceto sua preservação e disseminação.

- Os autores declaram que os necessários Termos de Consentimento Livre e Esclarecido de participantes ou pacientes na pesquisa foram obtidos e estão descritos no manuscrito, quando aplicável.

- Os autores declaram que a elaboração do manuscrito seguiu as normas éticas de comunicação científica.

- Os autores declaram que os dados, aplicativos e outros conteúdos subjacentes ao manuscrito estão referenciados.

- O manuscrito depositado está no formato PDF.

- Os autores declaram que a pesquisa que deu origem ao manuscrito seguiu as boas práticas éticas e que as necessárias aprovações de comitês de ética de pesquisa, quando aplicável, estão descritas no manuscrito.

- Os autores concordam que caso o manuscrito venha a ser aceito e postado no servidor SciELO Preprints, a retirada do mesmo se dará mediante retratação.

- Os autores concordam que o manuscrito aprovado será disponibilizado sob licença Creative Commons CCBY.

- O autor submissor declara que as contribuições de todos os autores e declaração de conflito de interesses estão incluídas de maneira explícita e em seções específicas do manuscrito.

- Os autores declaram que o manuscrito não foi depositado e/ou disponibilizado previamente em outro servidor de preprints ou publicado em um periódico.

- Caso o manuscrito esteja em processo de avaliação ou sendo preparado para publicação mas ainda não publicado por um periódico, os autores declaram que receberam autorização do periódico para realizar este depósito.

- O autor submissor declara que todos os autores do manuscrito concordam com a submissão ao SciELO Preprints.

Submetido em (AAAA-MM-DD): 2021-05-10

Postado em (AAAA-MM-DD): 2021-05-13 


\title{
PRODUZINDO A SUBALTERNIDADE: AS MERENDEIRAS NOS DOCUMENTOS E INICIATIVAS DA GESTÃO FEDERAL DO PNAE1
}

\author{
MARIANA BELLONI MELGAÇO² \\ https://orcid.org/0000-0003-2894-1120 \\ RODRIGO MATOS-DE-SOUZA ${ }^{3}$ \\ https://orcid.org/0000-0002-8788-4966
}

\begin{abstract}
RESUMO: Neste trabalho tratamos da merendeira, profissional responsável pelo preparo da alimentação escolar das escolas públicas brasileiras e que exerce papel fundamental para o atingimento dos objetivos do Programa Nacional de Alimentação Escolar (PNAE): contribuir para o crescimento e desenvolvimento biopsicossocial, para a aprendizagem, para o rendimento escolar e para a formação de hábitos alimentares saudáveis dos estudantes. Apesar da importância da merendeira para o Programa, o seu potencial educativo é muitas vezes invisibilizado e não reconhecido no âmbito escolar. Diante disso, este estudo teve como objetivo averiguar quais são os documentos e iniciativas desenvolvidos pela gestão federal do PNAE que envolvem a merendeira e se podem contribuir com a (des)valorização da sua profissão e sua manutenção como sujeito não participante das decisões no âmbito escolar, reforçando sua posição de subalternidade. A análise documental permitiu verificar que o Programa possui arcabouço legal para fortalecer e valorizar os papéis das merendeiras, especialmente no que se refere à função de educadora. Porém, a análise sugere que as ações ficam mais voltadas para o âmbito da inscrição no discurso oficial do que no da representação/representatividade, o que pode contribuir para o seu desprestígio social e a consolidação da sua função enquanto sujeito subalterno.
\end{abstract}

Palavras-chave: merendeira, educação alimentar, alimentação escolar, políticas públicas, educação.

\section{MAKING SUBALTANITY: THE LUNCH LADIES IN THE DOCUMENTS AND INITIATIVES OF THE FEDERAL ADMINISTRATION OF THE PNAE}

\begin{abstract}
This paper deals with the lunch lady (Merendeira), a professional responsible for preparing school meals in Brazilian public schools and who plays a key role in achieving the goals of the National School Meals Program (PNAE): to contribute to the biopsychosocial growth and development, learning, school performance and the formation of healthy eating habits of students. Despite the importance of the lunch lady for the program, her educational potential is often invisible and unrecognized in the school

\footnotetext{
${ }^{1} \mathrm{O}$ presente estudo recebeu financiamento através do Edital $01 / 2020$ de apoio à publicação científica do Programa de Pós-Graduação em Educação - Modalidade Profissional, como ação derivada do projeto Colonialismo/Colonialidade e educação: cenários de resistência e subordinação e do EDITAL DPG/UNB N ${ }^{\circ}$ 0002/2021 - Auxílio Financeiro a Estudantes de Pós-Graduação para o Desenvolvimento de Dissertações e Teses.

2 Fundo Nacional de Desenvolvimento da Educação (FNDE), Brasília, DF, Brasil. <mariana.melgaco@fnde.gov.br>

${ }^{3}$ Universidade de Brasília (UnB), Brasília, DF, Brasil. <rodrigomatos@unb.br>
} 
environment. Because of this, this study aimed to investigate what are the documents and initiatives developed by the federal management of PNAE that involve the lunch lady and if they can contribute to the (de)valorization of her profession and her maintenance as a subject that does not participate in the decisions in the school environment, reinforcing her subaltern position. The document analysis allowed to verify that the program has a legal framework to strengthen and enhance the roles of the lunch ladies, especially concerning the role of educator. However, the analysis suggests that the actions are more focused on the scope of registration in the official discourse than on representation/representation, which can contribute to their social discredit and the consolidation of their role as a subordinate subject.

Keywords: merendeira, food education, school feeding, public policies, education.

\section{PRODUCIENDO SUBALTERNIDAD: LAS COCINERAS EN LOS DOCUMENTOS E INICIATIVAS DE LA ADMINISTRACIÓN FEDERAL DEL PNAE}

RESUMEN: En este artículo abordamos a la comensal (Merendeira), profesional responsable de la preparación de las comidas escolares en las escuelas públicas brasileñas y que desempeña un papel fundamental en la consecución de los objetivos del Programa Nacional de Alimentación Escolar (PNAE): contribuir al crecimiento y desarrollo biopsicosocial, al aprendizaje, al rendimiento escolar y a la formación de hábitos alimentarios saludables de los alumnos. A pesar de la importancia de la señora del almuerzo para el programa, su potencial educativo suele ser invisible y no se reconoce en el entorno escolar. Ante esto, este estudio tuvo como objetivo investigar cuáles son los documentos e iniciativas desarrolladas por la dirección federal del PNAE que involucran a la comensal y si pueden contribuir a la (des)valoración de su profesión y a su mantenimiento como un sujeto que no participa en las decisiones dentro de la escuela, reforzando su posición de subalternidad. El análisis documental permitió comprobar que el programa cuenta con un marco legal para fortalecer y potenciar las funciones de las comensales, especialmente en lo que respecta al rol de educadora. Sin embargo, el análisis sugiere que las acciones se centran más en el alcance del registro en el discurso oficial que en la representación/representación, lo que puede contribuir a su descrédito social y a la consolidación de su papel como sujeto subalterno.

Palabra-clave: merendeira, educación alimentaria, alimentación escolar, políticas públicas, educación.

\section{INTRODUÇÃO}

De início, este estudo pretende lançar luz sobre uma figura subalterna, não nos entendam mal os que vêm de outros campos e não conhecem a expressão. Subalterno aqui diz respeito aos Estudos Subalternos, que se interessa por aqueles que no contexto da produção do colonial enquanto estrutura, foram silenciados, impedidos de falar e recolhidos ao interior para que sua expressão não ganhasse força fora dos domínios do popular, impedindo assim seu trânsito para além das linhas previamente desenhadas para sua mobilidade social - ou sua manutenção em um determinado estamento (SPIVAK, 2010; SPIVAK, 2013a).

O subalterno goza da mesma falta de prestígio social do popular, é seu equivalente em termos teóricos, tal como a classe está para a pobreza, como especula Spivak (2013b), enquanto uma palavra tende à racionalidade, a outra, à representação através do 
desejo. Neste artigo não pretendemos dar voz nem fazer representar o processo de exclusão que estamenta a merendeira nos fundos da escola, mas criar as condições, spivakianamente falando (2010), para que quando esse sujeito ${ }^{4}$ possa falar ele consiga ser ouvido, colaborando com a produção de massa crítica sobre o tema ${ }^{5}$, provocando a universidade para que perceba esses sujeitos, colaborando para que suas condições de chegada ao debate teórico não seja apenas como temática de interesse, mas ação que suscite uma concreta articulação enquanto grupo e a criação de condições para ser ouvido (SPIVAK, 2010; SAID, 2012). Ao lançar luz sobre essa figura subalterna pretendemos colaborar com uma leitura crítica de documentos que tratam diretamente do trabalho subalterno, mas dele se silencia, trabalhando em alguns documentos a produção dessa invisibilidade e em outros com o vestígio, a impropriedade etc.

Neste artigo trataremos de uma figura que todos aqueles que passaram por uma escola pública no Brasil conhecem por distintas alcunhas, todas elas acompanhadas por um substantivo feminino com função adjetiva: da merenda. Seja tia, moça ou mesmo chamada diretamente pela designação do cargo, a merendeira. São poucos os estudos direcionados a merendeira. Os realizados demonstram que a função de merendeira é exercida predominantemente por mulheres, pardas ou negras, de baixa escolaridade e pertencentes às classes sociais mais baixas (FERNANDES; FONSECA; SILVA, 2014; KUTZ, 2018; TEO; SABEDOT; SCHAFER, 2010; LIMA; CARVALHO, 2016). Essa mulher exerce posto fundamental na educação de milhões de crianças, jovens e adultos em nosso país, no entanto o interesse por ela não corresponde diretamente à importância de seu posto. Apresentaremos evidências disso através da leitura de dispositivos legais, regulamentares e organizadores das políticas públicas direcionadas à alimentação escolar brasileira.

A alimentação é parte essencial e constitutiva do ser humano e compõe aquilo que chamamos de cultura, em qualquer sociedade. Comer é um ato que extrapola a necessidade fisiológica. A comida relaciona as dimensões orgânica, intelectual, psicológica, cultural e espiritual, envolvendo a expressão e construção da nossa identidade (POLLAN, 2008; VALENTE, 2014), na medida em que através dos alimentos podemos ativar elementos da subjetividade que nos informam quem somos, onde quer que estejamos e uma política pública que pretende atuar diretamente em uma dimensão da cultura dos sujeitos, em sua alimentação, diz muito sobre como produzimos representações do que entendemos por nós mesmos.

O Programa Nacional de Alimentação Escolar (PNAE) é uma política pública de educação, com caráter social, vinculado ao Fundo Nacional de Desenvolvimento da Educação (FNDE) do Ministério da Educação (MEC). Sua origem data de 1955, sendo considerado um dos maiores programas na área de alimentação escolar do mundo, atendendo de forma universal e gratuita aos alunos matriculados na educação básica de escolas públicas, filantrópicas e comunitárias de todos os municípios do país (BRASIL, 1955, 2009 e 2020a).

Ao longo dos mais de 60 anos desde a sua implementação, o PNAE passou por diversas ressignificações e reestruturações que possibilitaram o seu fortalecimento (PEIXINHO, 2013). Atualmente é concebido como uma política pública de caráter universal, educacional, sustentável e saudável e está alinhado a um conjunto de ações estruturantes para promover o Direito Humano à Alimentação Adequada (DHAA) e a

\footnotetext{
${ }^{4}$ Utilizaremos aqui o termo sujeito por ser uma expressão do campo, traduzido do inglês subject, que não tem gênero originalmente em língua inglesa, mas, em língua portuguesa, ganha o gênero masculino. Essa dificuldade estará expressa ao longo do texto. Procuramos reduzir seu uso, mas foi inevitável. Respeitando a precedência, marcamos aqui que essa advertência tem lugar na obra de Grada Kilomba (2019), a qual fazemos menção ao produzir esta nota e dizer dessa dificuldade.

${ }^{5}$ Uma das autoras deste texto desenvolve dissertação de mestrado sobre as Merendeiras: MELGAÇO, Mariana Belloni. As Merendeiras do DF: Voz e Silêncio no Programa Nacional de Alimentação Escolar. Dissertação (Mestrado em Educação). Brasília: Universidade de Brasília.
} 
Segurança Alimentar e Nutricional ${ }^{6}$ (SAN). Por ser um Programa da educação em sentido amplo, nisso reside o seu potencial de transformação.

O marco legal do PNAE, Lei n 11.947, de 16 de junho de 2009 (BRASIL, 2009), define como sendo alimentação escolar a oferta, durante o período letivo, de todo e qualquer alimento no ambiente da escola. De acordo com o seu artigo quarto, o Programa deve contribuir tanto para o desenvolvimento biopsicossocial dos alunos, quanto para seu o rendimento escolar e para a formação de hábitos alimentares saudáveis. Tal objetivo deve ser cumprido não só pela oferta de refeições saudáveis, mas também por meio de ações de Educação Alimentar e Nutricional (EAN).

O PNAE ao possibilitar o acesso a uma alimentação diversificada e saudável contribui para o desenvolvimento escolar, pessoal e social, tanto dos escolares quanto aos que diretamente ou indiretamente estão ligados ao Programa (CASAGRANDE; CANCELIER; BELING, 2021). Além disso, o PNAE é considerado uma inovação em políticas públicas por associar a oferta da alimentação escolar saudável a iniciativas de compras sustentáveis, articuladas com o fortalecimento da agricultura familiar e com a SAN dos estudantes (KROTH; GEREMIA; MUSSIO, 2020).

Já as estratégias de EAN podem contribuir de forma eficiente na prevenção e no tratamento das doenças crônicas, sobrepeso e obesidade, desenvolvendo a capacidade crítica dos sujeitos para escolhas alimentares saudáveis e adequadas ao seu contexto sociocultural (SANTOS, 2016).

De acordo com Recine (2017), o PNAE tem passado por diversas melhorias tanto na qualidade da alimentação e na dinamização do desenvolvimento local quanto nas medidas direcionadas a ampliar e qualificar uma outra dimensão essencial do Programa que é a promoção da alimentação adequada e saudável por meio de estratégias de EAN.

A Resolução no 6, de 8 de maio de 2020 (BRASIL, 2020a), em seu artigo 14 ressalta a importância da inclusão da EAN no processo de ensino e aprendizagem. Esse fato deve perpassar de maneira transversal o currículo escolar, abordando o tema alimentação e nutrição e o desenvolvimento de práticas e habilidades que promovam modos de vida saudáveis, na perspectiva da SAN. Também define a EAN como:

$\int 1^{\circ}$ Para fins do PNAE, considera-se EAN o conjunto de ações formativas, de prática contínua e permanente, transdisciplinar, intersetorial e multiprofissional, que objetiva estimular a adoção voluntária de práticas e escolhas alimentares saudáveis que colaborem para a aprendizagem, o estado de saúde do escolar e a qualidade de vida do indivíduo (BRASIL, 2020a, p. 6).

O PNAE é regido por normativos legais que fornecem embasamento robusto para a implantação da EAN em âmbito escolar. As ações de EAN, por sua vez, são imprescindíveis pra que o Programa atinja os seus objetivos: contribuir para o crescimento e o desenvolvimento biopsicossocial, a aprendizagem, o rendimento escolar e a formação de práticas alimentares saudáveis dos alunos (BRASIL, 2009).

Além de todo o amparo legal que o PNAE confere à EAN nas escolas, existem documentos e normativos que fortalecem e fundamentam a EAN como o Marco de Referência Marco de Referência de Educação Alimentar e Nutricional para as Políticas Públicas (BRASIL, 2012). O lançamento do Marco reforça as iniciativas criadas pelo FNDE que se destinam à promoção do DHAA, propondo que os processos educativos sejam duradouros e que favoreçam a promoção de autocuidado e autoestima, que as ações contemplem todo o sistema alimentar e que haja diálogo e escuta para uma prática de EAN

\footnotetext{
${ }^{6}$ A Segurança Alimentar e Nutricional consiste na realização do direito de todos ao acesso regular e permanente a alimentos de qualidade, em quantidade suficiente, sem comprometer o acesso a outras necessidades essenciais, tendo como base práticas alimentares promotoras de saúde que respeitem a diversidade cultural e que sejam ambiental, cultural, econômica e socialmente sustentáveis (BRASIL, 2006, p.01).
} 
respeitosa, democrática e sintonizada com as reais necessidades dos grupos populacionais e com as mudanças sociais.

A publicação da Portaria Interministerial no 1.010, de 8 de maio de 2006, pelos Ministérios da Saúde e da Educação instituiu as diretrizes para a promoção da alimentação saudável na educação básica, das redes pública e privada, sendo a EAN afirmada como um dos eixos prioritários de ação (BRASIL, 2006). Já a Lei no 13.666, de 16 de maio de 2018, alterou a Lei no 9.394, de 20 de dezembro de 1996 (BRASIL, 1996), a Lei de Diretrizes e Bases da Educação Nacional (LDB), para incluir a educação alimentar e nutricional como tema transversal no currículo escolar. Essa lei trouxe a obrigatoriedade de os currículos do ensino fundamental e médio incluírem o tema da educação alimentar e nutricional nas disciplinas de ciências e biologia, respectivamente (BRASIL, 2018).

Para alcançar uma alimentação saudável no ambiente escolar, a Portaria recomenda a implementação de diversas ações como o envolvimento de toda a comunidade escolar para a definição de estratégias que favoreçam escolhas saudáveis, a sensibilização e capacitação dos profissionais envolvidos com alimentação na escola para produzir e oferecer alimentos mais saudáveis. Além disso, propõe também a incorporação do tema alimentação saudável no projeto político pedagógico (PPP) da escola, perpassando todas as áreas de estudo e propiciando experiências no cotidiano das atividades escolares.

Estudos realizados indicam a importância de se incluir a EAN no PPP das escolas, permitindo que a construção de conteúdos programáticos para a alimentação escolar sejam experiências tanto mais ricas quanto mais participativas (CASEMIRO; FONSECA; MACHADO; PERES, 2015).

Em um estudo realizado em municípios do estado de Goiás para identificar e caracterizar as ações de EAN no PNAE foi verificado que a maioria possui o tema no PPP das escolas, e que $91,1 \%$ dos municípios realizavam ações de EAN, porém com frequência semestral (ações pontuais) e utilizando predominantemente métodos passivos de ensinoaprendizagem. E apesar das conquistas da área, permanece a lacuna entre o discurso teórico e a prática educativa (SILVA; MONEGO; SOUSA; ALMEIDA, 2018).

Resultados semelhantes foram encontrados em um estudo realizado com 749 municípios que participaram do Prêmio Gestor Eficiente da Merenda Escolar no ano de 2010. Ottoni, Oliveira e Bandoni (2019) verificaram que a maioria dos municípios relatou a presença de EAN no currículo escolar, porém menos da metade utilizou algum método ativo, sendo a horta escolar o mais referido. A presença de EAN no currículo escolar foi associado positivamente à execução de hortas, resultado que demonstra a importância da presença de conteúdos em alimentação e nutrição nos currículos pedagógicos das escolas brasileiras.

Araújo et. al (2017) realizaram uma revisão sistemática de artigos e trabalhos científicos acerca do impacto da EAN nas ações de prevenção e controle do excesso de peso entre os escolares entre os anos de 2005 e 2015 no país. Os resultados dos estudos apontaram para mudanças no comportamento alimentar dos escolares e melhoria do conhecimento sobre a alimentação saudável.

O estudo também verificou baixo número de trabalhos científicos publicados na temática da EAN no período pesquisado. Os autores concluíram que as ações de EAN devem ser fomentadas e reconheceram a necessidade de realização de novas pesquisas na área, especialmente de estudos que consideram em sua metodologia a cultura de valores, crenças e atitudes dos sujeitos que estejam relacionados à alimentação.

Santos $(2005 ; 2012)$ observou a crescente importância dada à educação alimentar e nutricional nos documentos que elaboram as políticas públicas no campo da alimentação e nutrição no Brasil. Apesar do avanço nos discursos sobre o tema, o mesmo avanço não é percebido nas práticas cotidianas desenvolvidas pelos profissionais no campo da EAN.

De acordo com os estudos apontados e os documentos e instrumentos normativos (BRASIL, 2012, 2020a), para que a EAN seja efetiva, deve ocorrer de forma 
interdisciplinar e transdisciplinar e envolver toda a comunidade escolar. Dentre os funcionários da escola e os sujeitos do PNAE estão, justamente, as merendeiras.

As merendeiras são responsáveis pelo preparo e distribuição da alimentação escolar. Porém, o papel que desempenham dentro da escola não se limita ao preparo dos alimentos e a higienização das áreas físicas - mesmo que esses papéis muito além do trabalho de manipulação de alimentos não sejam reconhecidos pelos outros sujeitos da educação ou encontre escassa representação nos marcos legais que analisaremos. As merendeiras mantêm contato diário e direto com os estudantes, exercendo um papel fundamental na educação alimentar e nutricional e na formação de hábitos alimentares saudáveis dos escolares. Esse fato, aliado ao contato com o estudante dentro da escola, cria um vínculo afetivo, por vezes subestimado pelo próprio sistema educativo, que coloca a merendeira em uma função primordial de educadora em termos culturais.

Ao realizar uma revisão sistematizada sobre a EAN, Santos (2016) verificou que abordagem da EAN no contexto da alimentação escolar está muito aquém de se realizar de uma maneira interdisciplinar e dentro de uma proposta problematizadora e dialógica. Isso ocorre pela formação inadequada do nutricionista que é baseada num modelo tecnicista e biomédico, pelo baixo comprometimento dos gestores e também pela ausência de diálogo entre os sujeitos envolvidos no PNAE.

Outro estudo de revisão sobre EAN no ambiente escolar, realizada por Borsoi, Teo e Mussio (2016) identificou que um dos grandes entraves da EAN pode ser a lógica reducionista da transmissão de informação. Devem ser buscados e utilizados mecanismos inovadores de promoção de hábitos alimentares saudáveis transversais, contextualizados e melhor sucedidos.

Pedraza et. al (2018) ao realizarem uma análise sumária das pesquisas avaliativas sobre o PNAE verificaram que a atuação das merendeiras foi um dos temas pouco abordados. A inadequação no planejamento e na gestão do Programa prejudica a atuação das merendeiras, apesar de serem reconhecidamente essenciais ao PNAE.

Por exercer um papel tão estratégico dentro da escola e do PNAE, este estudo tem como objetivo averiguar quais são os documentos, ações e normativos do Programa que se relacionam com o papel da merendeira e analisar se eles podem contribuir com a (des)valorização da sua profissão e sua manutenção como sujeito não participante das decisões no âmbito escolar, reforçando sua posição de subalternidade num contexto em que exerce função primordial e relevante para a formação de futuras gerações.

\section{METODOLOGIA}

Para entender melhor os papéis da merendeira, consideramos necessário analisar quais são os documentos, legislações e projetos do PNAE que se relacionam com essa profissional. Para tanto, foram selecionados os normativos vigentes e as iniciativas dos últimos cinco anos desenvolvidos pela gestão federal do PNAE. A análise desses documentos favorece um olhar ampliado sobre a função que a merendeira exerce no PNAE e como podem influenciar o papel assumido por elas.

Para esta pesquisa serão analisados os seguintes itens, a saber:

QUADRO 1 - Descrição dos itens analisados na pesquisa documental:

$$
\text { Itens analisados } \quad \text { Tipo }
$$

Lei $\mathrm{n}^{\circ}$ 11.947, de 16 de junho de 2009 Legislação

Resolução/CD/FNDE n $^{\circ}$ 6, de 8 de maio de 2020 e Legislação

Resolução/CD/FNDE n' 20, de 2 de dezembro de 2020 


\begin{tabular}{|l|c|}
\hline Notas técnicas do PNAE & Normativo \\
\hline $\begin{array}{l}\text { Material orientativo para formação de manipuladores de } \\
\text { alimentos que atuam na alimentação escolar }\end{array}$ & Manual \\
\hline $\begin{array}{l}\text { Produtos técnicos dos CECANEs } \\
\text { Concurso “Melhores Receitas da Alimentação Escolar” }\end{array}$ & Produto \\
\hline Super Merendeiras & Projeto \\
\hline Jornada de EAN & Programa de televisão Reality Show \\
\hline Quarta capa dos livros didáticos & Projeto de EAN \\
\hline Questionário de Monitoramento do PNAE & Projeto de EAN \\
\hline
\end{tabular}

Fonte: Elaborado pelos autores, 2021.

A análise dos documentos partiu da necessidade de compreender o lugar das merendeiras no conjunto de documentos do PNAE. Em tais documentos buscamos pela nomenclatura merendeira, bem como por merend*, e termos correlatos como alimentação, alimentando, refeição etc. que poderiam nos indicar também o modo como os autores de tais dispositivos normativos se apropriaram dessa categoria (CHARTIER, 2003), entendoos como uma apropriação oficial que acabam por orientar políticas nacionais, regionais, estaduais e municipais em torno da alimentação escolar. A partir desse levantamento cotejamos o material levantado com autores que vem estudando a EAN (CASEMIRO; FONSECA; MACHADO; PERES, 2015; OTTONI; OLIVEIRA; BANDONI, 2019; SANTOS, 2005; 2012), o PNAE (CASAGRANDE; CANCELIER; BELING, 2021; KROTH; GEREMIA; MUSSIO, 2020; RECINE, 2017) nacionalmente e, preferencialmente, dialogamos com a tradição crítica dos Estudos Subalternos, por entendermos haver eco entre a posição do sujeito subalterno nos arranjos da colonialidade e o lugar ocupado pela merendeira nos espaços escolares ao mesmo tempo em que funciona como um marco político para as interpretações (SPIVAK, 2013a) a partir das quais podemos dar algumas explicações aos acontecimentos. Para o desenvolvimento desse estudo, também, entendemo-nos como bricoleurs (KINCHELOE; BERRY, 2007; MATOS-DE-SOUZA et al., 2021), acionando diferentes tradições teóricas quando essas responderam mais adequadamente ao fenômeno estudado.

\section{O QUE DIZEM OS DOCUMENTOS}

\section{A Lei n ${ }^{\circ}$ 11.947/2009: tratando da formação sem dizer do sujeito em formação}

A Lei no 11.947/2009 (BRASIL, 2009), marco legal do PNAE, não possui nenhum artigo específico sobre a atuação das merendeiras ou manipuladores de alimentos sendo essa última expressão objeto de crítica neste artigo. Apesar de essas mulheres exercerem importante papel e serem reconhecidas como sujeitos do processo de formação segundo o dispositivo legal, não ganham representação no marco legal. Porém, a referida lei ressalta a responsabilidade do FNDE de capacitar os sujeitos envolvidos na execução da alimentação escolar:

Artigo 16. Competem à União, por meio do FNDE, autarquia responsável pela coordenação do PNAE, as seguintes atribuições:

VI - Cooperar no processo de capacitação dos recursos humanos envolvidos na execução do PNAE e no controle social (BRASIL, 2009). 
A merendeira, pertencendo ao grupo de sujeitos envolvidos na execução do PNAE, deve receber capacitação promovida pelo FNDE no âmbito do Programa conforme previsto em Lei. A capacitação dessas profissionais pode ocorrer, por exemplo, via nutricionistas. No Manual de apoio para atividades técnicas do nutricionista no âmbito do PNAE (FNDE, 2018), documento que norteia a atuação do nutricionista do PNAE, o nutricionista é instigado a agir em parceria com a comunidade escolar, fortalecer e disseminar as ações e ideias sobre EAN na escola.

De acordo com a Resolução do Conselho Federal de Nutricionistas no 465/2010 (CFN, 2010), que dispõe sobre as atribuições do nutricionista da alimentação escolar destacase em relação a capacitação que:

Art. $3^{\circ}$ Compete ao nutricionista, vinculado à Entidade Executora, no âmbito do Programa de Alimentação Escolar (PAE), exercer as seguintes atividades obrigatórias:

IV. Propor e realizar ações de educação alimentar e nutricional para a comunidade escolar, inclusive promovendo a consciência ecológica e ambiental, articulandose com a direção e com a coordenação pedagógica da escola para o planejamento de atividades com o conteúdo de alimentação e nutrição;

X. Orientar e supervisionar as atividades de higienização de ambientes, armazenamento de alimentos, veículos de transporte de alimentos, equipamentos e utensílios da instituição;

VI. Planejar, orientar e supervisionar as atividades de seleção, compra, armazenamento, produção e distribuição dos alimentos, zelando pela quantidade, qualidade e conservação dos produtos, observadas sempre as boas práticas higiênico-sanitárias;

Art. $4^{\circ}$ Compete ao nutricionista, vinculado à Entidade Executora, no âmbito do Programa de Alimentação Escolar (PAE), exercer as seguintes atividades complementares:

I. Coordenar, supervisionar e executar ações de educação permanente em alimentação e nutrição para a comunidade escolar

IV. Participar do recrutamento, seleção e capacitação de pessoal que atue diretamente na execução do PAE;

V. Participar de equipes multidisciplinares destinadas a planejar, implantar, implementar, controlar e executar políticas, programas, cursos, pesquisas e eventos na área de alimentação escolar;

VII. Colaborar na formação de profissionais na área de alimentação e nutrição, supervisionando estagiários e participando de programas de aperfeiçoamento, qualificação e capacitação (CFN, 2010).

Conforme amparado em legislação, a capacitação de merendeiras, além de ser essencial para a boa execução do PNAE, deve ser uma ação articulada entre gestores da alimentação escolar e nutricionistas. Cada escola e município possui uma realidade que é conhecida pelo nutricionista, reconhece-se o papel cultural desempenhado pelo formador, na mesma medida em que se silencia quanto ao sujeito que lida diretamente com a cozinha da escola. Além disso, de acordo com as atribuições previstas na Resolução CFN n ${ }^{\circ}$ 465/2010 (CFN, 2010), o nutricionista trabalha em um conjunto de ações técnicas do PNAE se envolvendo em diversas atividades da alimentação escolar.

O nutricionista enquanto responsável técnico do PNAE deve trabalhar em conjunto com a área da educação, promovendo a articulação entre os saberes da saúde com os saberes educacionais. Ao articular e compor essas interlocuções o nutricionista ressignifica a sua atuação para uma possibilidade de transformação social.

Todas as atribuições do nutricionista e o fato dele estar inserido no contexto escolar e do município, conhecendo a sua realidade e atuando no microcosmo o habilita como um importante agente de capacitação dos sujeitos envolvidos na alimentação escolar. 
A capacitação das merendeiras é uma das atribuições do nutricionista do PNAE. Cabe ao FNDE promover ações que habilitem e instiguem os nutricionistas nessa tarefa. Ressaltando que a capacitação não deve focar apenas as questões sanitaristas, mas fortalecer o papel da merendeira enquanto educadora alimentar e nutricional.

\begin{abstract}
Investimentos governamentais são necessários para a formulação, a implementação e a avaliação de políticas públicas que incentivem a promoção e a manutenção da alimentação adequada e saudável no ambiente escolar. Ênfase deverá ser dada ao financiamento adequado na execução do Programa e na formação continuada dos atores envolvidos com a coordenação e a execução das ações de EAN (SILVA; MONEGO; SOUSA; ALMEIDA, 2018, p. 2679).
\end{abstract}

A capacitação de nutricionistas implica não só na revisão das suas atribuições legalmente previstas, como também na reflexão sobre o alcance de uma educação alimentar e nutricional pautada pela legislação do PNAE (BRASIL, 2009; 2020a) e pelo Marco de Referência de Educação Alimentar e Nutricional para as Políticas Públicas (BRASIL, 2012). Esses documentos reforçam a importância dos saberes multiprofissionais, transversais e interdisciplinares, possibilitando a criação de um olhar mais sensível do nutricionista para os profissionais da comunidade escolar, destacando-se as merendeiras.

A qualificação das merendeiras, não só em termos operacionais, mas também em relação ao processo pedagógico que envolve a oferta da alimentação escolar é item de suma importância para a efetivação da educação alimentar e nutricional prevista no PNAE. A qualificação periódica das merendeiras possibilita uma alimentação escolar de qualidade e o cumprimento de uma das diretrizes do Programa (PINHO; MARTÍNEZ, 2016).

Para Santos (2016), a capacitação em EAN dos atores envolvidos na promoção da saúde no ambiente escolar possibilita o compartilhamento de vivências e experiências, o embasamento teórico e a elaboração de estratégias para a promoção e oferta da alimentação adequada e saudável. Os cursos, oficinas e grupos de discussão devem estar baseados numa abordagem sócio construtiva e problematizadora, abandonando os modelos tradicionais e pouco dialógicos tão frequentemente utilizados. Para os autores, o nutricionista é o profissional habilitado para capacitar e sensibilizar os outros atores em EAN.

Kroth, Geremia e Mussio (2020) ao analisarem o PNAE enquanto Política Pública Saudável que se traduz em grandes retornos para a sociedade sugerem mecanismos que devem estar articulados entre si para o aprimoramento e o fortalecimento do Programa. Dentre as ações indicadas está a elaboração de um plano de capacitação técnica do PNAE para entes federados, envolvendo todos dos atores do Programa tais como nutricionistas, merendeiras e professores. "Em tempos em que se discute muito o uso racional de recursos governamentais, priorizar políticas públicas com grande efeito multiplicador devem ser o caminho natural a ser seguido pelo setor público" (p. 4073).

Entendemos que o trabalho concreto da merendeira, cujo perfil é muito próximo das trabalhadoras da cozinha em nosso país, que intersecciona raça e gênero (JANUÁRIO et al, 2019) e indo além de carregar nessa intersecção marcas que a subalternizam em um contexto marcado pela colonialidade do pensamento, e representa também sua variedade de seu fazer do escopo do precariado (STANDING, 2017), cuja formação permanente, promovida por agentes externos pouca relação guarda com seu fazer cotidiano.

Elas ficaram de fora dos termos da Lei no 11.947/2009 (BRASIL, 2009), o que nos permite ler o seu não lugar, no campo do discurso, dos sujeitos que efetivamente programam a política pública no âmbito escolar. Muitos dos processos de opressão e violência pelas quais passam as mulheres e, em especial, as mulheres negras, no âmbito do trabalho surgem processos como esses, nos quais o sujeito ativo do processo é completamente invisibilisado, é uma primeira violência que autoriza outras dentro dessa relação, que nas duras palavras de Collins (2019) reproduzem o lugar da mulher negra, em 
posição subalterna como a mula do mundo: "Como objetos desumanizados, as mulas são máquinas vivas e podem ser tratadas como parte da paisagem” (p.99). A paisagem, no contexto escolar contém uma cozinha e nessa está a merendeira, como parte do maquinário e dos utensílios, nem sequer figura na lei que trata de sua própria formação.

\section{Resolução/CD/FNDE n ${ }^{\circ}$ 6/2020 e Resolução/CD/FNDE no 20/2020: da redução à expressão técnica}

A Resolução no 6/2020 (BRASIL, 2020a) dispõe sobre o atendimento da alimentação escolar aos alunos da educação básica no âmbito do PNAE e embora represente um avanço, pois menciona textualmente as merendeiras, o faz ignorando todo o processo de produção do imaginário das mulheres que atuam nas cozinhas das escolas, que aparecem no dispositivo como manipuladora de alimentos, uma redução do sujeito e de seu papel na comunidade escolar à letra fria da lei. Ao analisar esta legislação, é possível verificar que a atuação da merendeira é abordada nos seguintes artigos:

Art. 14 É de responsabilidade da Seduc, da Prefeitura Municipal e da escola federal, no âmbito de sua respectiva jurisdição administrativa, mediante atuação coordenada dos profissionais de educação e do responsável técnico e demais nutricionistas, a inclusão da educação alimentar e nutricional - EAN no processo de ensino e aprendizagem, que perpassa de maneira transversal o currículo escolar, abordando o tema alimentação e nutrição e o desenvolvimento de práticas e habilidades que promovam modos de vida saudáveis, na perspectiva da segurança alimentar e nutricional.

Art. 42 Cabe às EEx ou às UEx adotar medidas de controle higiênico-sanitário que garantam condições físicas e processos adequados às boas práticas de manipulação e processamento de alimentos na aquisição, no transporte, na estocagem, no preparo/manuseio e na distribuição de alimentos aos alunos atendidos pelo Programa.

$\int 2^{\circ}$ Deve haver capacitação periódica dos manipuladores de alimentos com vistas à implementação das boas práticas e dos POPs $^{7}$ (BRASIL, 2020a).

No que tange a EAN, a referida resolução referencia que é necessária a atuação conjunta dos profissionais de educação e dos nutricionistas da alimentação escolar. Entendendo a merendeira como funcionária da educação, é possível verificar que a legislação reconhece seu papel estratégico na implementação de ações de educação alimentar e nutricional integradas no processo de ensino e aprendizagem da escola.

Já o artigo 42 reforça a importância de medidas que garantam a oferta de uma alimentação saudável e dentro das condições higiênico-sanitárias adequadas. Para que isso ocorra é fundamental que haja a capacitação de merendeiras, como abordamos no item anterior. Porém, neste artigo que menciona explicitamente funções dos manipuladores de alimentos há um alerta apenas para a questão técnica e higienista do trabalho das merendeiras, não havendo nenhuma menção sobre a sua atuação enquanto educadora da alimentação escolar. Para que a educação alimentar e nutricional seja efetiva, é primordial que as merendeiras estejam qualificadas tanto na questão operacional quanto no que se relaciona com as questões educativas do seu trabalho e sejam reconhecidas como tal.

A Resolução no 20/2020 (BRASIL, 2020b) altera alguns itens da Resolução no 6/2020 (BRASIL, 2020a), mas a análise indicou que não houve alteração sobre os pontos abordados neste estudo.

\footnotetext{
${ }^{7}$ POPs: Procedimentos Operacionais Padronizados.
} 


\section{Notas técnicas do PNAE: da invisibilidade normativa}

O PNAE conta atualmente com quinze notas técnicas que tem como objetivo ratificar entendimentos, esclarecer a legislação do Programa, subsidiar o monitoramento e atender a demandas externas como as do Ministério Público, denúncias, dentre outras. As notas técnicas (FNDE, 2021) são elaboradas pela Coordenação do PNAE e auxiliam a boa execução do Programa. Esses documentos estão disponíveis para acesso e consulta no site do FNDE. Abaixo segue quadro contendo a descrição das notas técnicas elaboradas pela Coordenação do PNAE:

QUADRO 2 - Descrição das notas técnicas referentes ao PNAE elaboradas pela Coordenação do PNAE:

\begin{tabular}{|c|c|}
\hline Notas Técnicas & Descrição \\
\hline Nota Técnica nº 2139545/2020 & $\begin{array}{l}\text { Alterações dos aspectos de Alimentação e Nutrição e da Agricultura } \\
\text { Familiar dispostos na Resolução CD/FNDE n }{ }^{\circ} \text { 20, de } 2 \text { de dezembro } \\
\text { de } 2020\end{array}$ \\
\hline Nota Técnica nº 1894784/2020 & $\begin{array}{l}\text { Atualização das recomendações para o planejamento de cardápios das } \\
\text { creches atendidas pelo Programa Nacional de Alimentação Escolar - } \\
\text { PNAE }\end{array}$ \\
\hline Nota Técnica nº 1894673/2020 & $\begin{array}{l}\text { Atualização das recomendações acerca da alimentação vegetariana no } \\
\text { Programa Nacional de Alimentação Escolar - PNAE }\end{array}$ \\
\hline Nota Técnica nº 1897361/2020 & $\begin{array}{l}\text { Alterações dos aspectos da Agricultura Familiar da Resolução } \\
\text { CD/FNDE no 6, de } 8 \text { de maio de } 2020\end{array}$ \\
\hline Nota Técnica nº 1879810/2020 & $\begin{array}{l}\text { Alterações dos aspectos de Alimentação e Nutrição e de Segurança } \\
\text { Alimentar e Nutricional da Resolução CD/FNDE n }{ }^{\circ} \text { 6, de } 8 \text { de maio de } \\
2020\end{array}$ \\
\hline Nota Técnica No 5007/2016 & $\begin{array}{l}\text { Especificação de gêneros alimentícios para o Programa Nacional de } \\
\text { Alimentação Escolar - PNAE }\end{array}$ \\
\hline Nota Técnica no 5006/2016 & Aquisição de água mineral envasada pelo PNAE \\
\hline Nota Técnica no 5004/2016 & $\begin{array}{l}\text { Esclarecimentos sobre a aquisição de gêneros alimentícios para o PNAE } \\
\text { diretamente da Agricultura Familiar }\end{array}$ \\
\hline Nota Técnica No 5003/2016 & Aquisição de gêneros alimentícios diretamente da agricultura familiar \\
\hline Nota Técnica n ${ }^{\circ} 5002 / 2016$ & Controle de Estoque de alimentos no PNAE \\
\hline Nota Técnica nº $03 / 2014$ & Repasse financeiro do PNAE para o Programa Mais Educação \\
\hline Nota Técnica nº $02 / 2014$ & Aquisição de leite em pó para a alimentação escolar \\
\hline Nota Técnica n ${ }^{\circ} 04 / 2013$ & Inclusão de pescado na alimentação escolar \\
\hline Nota Técnica no 01/2013 & $\begin{array}{l}\text { Obrigatoriedade da pasteurização do leite para aquisição e oferta na } \\
\text { Alimentação Escolar }\end{array}$ \\
\hline Nota Técnica nº $02 / 2012$ & Regulamentação de cantinas escolares em escolas públicas do Brasil \\
\hline Nota Técnica no 01/2012 & $\begin{array}{l}\text { Posicionamento da Coordenação Geral do Programa de Alimentação } \\
\text { Escolar a respeito da aquisição de suco de laranja para a alimentação } \\
\text { escolar }\end{array}$ \\
\hline Nota Técnica nº 01/2011 & $\begin{array}{l}\text { Posicionamento da COTAN em relação às bebidas à base de frutas em } \\
\text { substituição à fruta na alimentação escolar }\end{array}$ \\
\hline Nota Técnica n ${ }^{\circ} 01 / 2009$ & Minuta sobre a parte de Nutrição da Resolução 38/2009 \\
\hline
\end{tabular}

Ao analisar as notas técnicas, é possível verificar que não há nenhuma que aborde diretamente as funções ou papéis das merendeiras no Programa. Os documentos disponibilizados do ano de 2009 a 2020 abordam questões referentes a alimentos, cardápios, agricultura familiar, dentre outros temas. Mas até o momento não incluíram nenhum assunto referente a educação alimentar e nutricional, uma das diretrizes do Programa e nem sobre a merendeira que possui um papel estratégico para a boa execução do PNAE.

Notas técnicas que reforcem a importância da educação alimentar e nutricional para o PNAE e o papel educativo da merendeira podem colaborar com a melhoria da gestão 
do Programa e com o atendimento de suas diretrizes. A ausência de nota técnica sobre merendeira ou sobre EAN corrobora com a invisibilização desta profissional.

\section{Material orientativo para formação de manipuladores de alimentos que atuam na alimentação escolar}

O Material orientativo para formação de manipuladores de alimentos que atuam na alimentação escolar (BRASIL, 2014) é um documento financiado e publicado pelo MEC/FNDE. Foi elaborado pelo Centro Colaborador Alimentação e Nutrição do Escolar (CECANE) da Universidade Federal do Rio Grande do Sul (UFRGS) no ano de 2014.

O material tem como objetivo principal “(...) fornecer embasamento teórico e científico subsidiando o planejamento e realização da formação de manipuladores de alimentos do PNAE" (BRASIL, 2014, p. 7). O material apresenta também sugestões de atividades práticas.

No capítulo 2, Formação de Manipuladores, o material traz uma reflexão sobre o papel de educador do manipulador de alimentos (BRASIL, 2014). Item importantíssimo, mas que poderia ser melhor explorado. Também aponta as atividades que podem ser desenvolvidas pelo manipulador de alimentos nas escolas. Segue quadro contendo a descrição das possíveis atividades do manipulador de alimentos disponível no material orientativo:

QUADRO 3 - Descrição das possíveis atividades do manipulador de alimentos do PNAE:

\begin{tabular}{|c|c|}
\hline & $\begin{array}{l}\text { Garantir aos escolares uma alimentação de qualidade, tanto no que se refere à questão nutricional } \\
\text { quanto a higiênico-sanitária; }\end{array}$ \\
\hline & Auxiliar na formação de hábitos alimentares saudáveis (papel de educador); \\
\hline & $\begin{array}{l}\text { Produzir refeições, através do cumprimento dos cardápios, seguindo as fichas técnicas (receitas) e } \\
\text { as boas práticas de manipulação; }\end{array}$ \\
\hline & Ofertar a alimentação produzida, promovendo o consumo adequado dos alimentos; \\
\hline & Auxiliar na aplicação de teste de aceitabilidade; \\
\hline & $\begin{array}{l}\text { Executar tarefas ligadas à área de pré-preparo e preparo de alimentos e distribuição de refeições, } \\
\text { seguindo as instruções contidas no manual de boas práticas, entre elas: Recebimento, higienização } \\
\text { e armazenamento dos alimentos, zelando pela qualidade dos mesmos; Controle de estoque } \\
\text { (organização, validade e quantidade dos produtos); Controle de temperatura; Coleta de amostra; } \\
\text { Higienização dos utensílios e equipamentos (quando não há um profissional específico); } \\
\text { Higienização do ambiente (quando não há um profissional específico). }\end{array}$ \\
\hline & $\begin{array}{l}\text { Comunicar irregularidades do PNAE aos responsáveis legais, uma vez que também faz parte do } \\
\text { controle social. }\end{array}$ \\
\hline
\end{tabular}

Fonte: Material orientativo para formação de manipuladores de alimentos que atuam na alimentação escolar (BRASIL, 2014, p.15). Elaborado pelos autores.

A elaboração e a divulgação de materiais como o citado acima contribuem para a formação da merendeira - nos materiais sempre tratada por manipuladora de alimentos - e também para o fortalecimento do seu papel dentro da escola. Sua função de educadora deve ser sempre reforçada tanto para a própria profissional como para os demais sujeitos do PNAE que tem acesso a esses documentos. A revisão e atualização deste material, lançado em 2014, pode colaborar com a valorização da merendeira. 


\section{Produtos técnicos dos CECANEs}

O FNDE firma parcerias com universidades públicas federais por meio dos CECANEs para o desenvolvimento de produtos técnicos para o PNAE. Um dos produtos técnicos foi o desenvolvimento de uma metodologia de capacitação de merendeiras pelo CECANE UFRGS no ano de 2007. Foram realizados cursos para 226 manipuladores vinculados à Secretaria Estadual de Educação do Rio Grande do Sul, em 2007 e 2008 (BRASIL, 2014).

Chaves (2011) realizou uma pesquisa sobre a capacitação de merendeiras na perspectiva de educadoras e promotoras da alimentação saudável nas escolas nos processos de formação realizados pelos CECANEs. Verificou que existe a valorização das merendeiras, por meio da motivação e sensibilização e que há preocupação de estimular a reflexão sobre a própria prática e incentivar a criatividade frente as suas possibilidades de execução da alimentação. A autora reforça a necessidade de que as atividades de educação sejam permanentes, o que possibilita o desenvolvimento de habilidades e atitudes dessas profissionais.

Camozzi, Monego, Menezes e Silva (2015) destacam a importância de espaços que ofereçam educação permanente para merendeiras e outros sujeitos da comunidade escolar para o desenvolvimento de ações de promoção de alimentação saudável no ambiente escolar:

Parece evidente a necessidade de programas de educação permanente que abordem não somente temas relacionados à higiene na manipulação dos alimentos, como também formas de preparo, estrutura de cardápio, buscando a compreensão do papel do manipulador como agente promotor da alimentação saudável no espaço escolar, oferecendo preparações saudáveis e variadas, além de contemplar aspectos culturais do público consumidor, restringindo a oferta de alimentos com excesso de gordura, açúcar ou sal (p. 36).

Atualmente não são mais firmados produtos técnicos que visem a capacitação de merendeiras. A coordenação do PNAE tem focado a capacitação de nutricionistas. Como o treinamento de merendeiras é uma das atribuições do nutricionista da alimentação escolar, conforme consta na Resolução CFN no 465/2010 (CFN, 2010), o FNDE tem optado pela formação de nutricionistas, como já discutimos acima, a falta de formação dedicada e específica para esse sujeito, dentro das ações do PNAE, subalterniza as merendeiras em relação às nutricionistas.

Cabe o questionamento e a reflexão se não seria importante retomar a capacitação de merendeiras pelos CECANEs que possuem arcabouço técnico, operacional e intelectual para realizar esse produto técnico. E que poderão realizar capacitações periódicas de merendeiras tanto no que se refere às questões sanitárias e higienistas, mas especialmente nas questões educativas, fortalecendo seu papel estratégico na promoção da alimentação saudável e adequada.

\section{Concurso "Melhores Receitas da Alimentação Escolar"}

O Concurso "Melhores Receitas da Alimentação Escolar" aconteceu em duas edições. A primeira edição ocorreu no ano de 2015 e a segunda em 2017. Consistiu na escolha, divulgação e premiação de receitas culinárias elaboradas por merendeiras da alimentação escolar que atuam em escolas públicas de educação básica (BRASIL, 2015; FNDE, 2017). 
O objetivo do concurso foi "valorizar o papel das merendeiras e merendeiros na promoção da alimentação saudável e adequada no ambiente escolar e promover a mobilização da comunidade escolar para a temática da educação alimentar e nutricional" (BRASIL, 2015; FNDE, 2017).

A primeira edição contou com a inscrição de 2.433 merendeiras. Cinco tiveram suas receitas premiadas e receberam o valor de $\mathrm{R} \$ 5.000,00$ (cinco mil reais) cada além de uma viagem para Santiago do Chile, com duração de uma semana. A segunda edição recebeu 2.252 inscrições. Foram premiadas quinze merendeiras com valores pagos em dinheiro e para as primeiras colocadas, além do dinheiro, viagens internacionais. As receitas premiadas tanto da primeira quanto da segunda edição deram origem a duas publicações do FNDE.

Esta ação promovida pela Coordenação do PNAE foi um projeto totalmente voltado para as merendeiras. Acreditamos que ações como essa ajudam a dar visibilidade para essas profissionais, sendo uma forma de valorização e reconhecimento do seu trabalho. Mas precisamos questionar a abrangência dessa ação. E se de fato conseguem melhorar o trabalho das merendeiras. Para isso seriam necessários estudos e pesquisas capazes de abordar em específico o impacto dessas ações.

\section{Super Merendeiras}

O reality show 'Super Merendeiras" foi um programa de televisão desenvolvido pelo FNDE com apoio do Banco do Brasil. Ocorreu no ano de 2018, mostrando uma competição entre as dez vencedoras da primeira e da segunda edição do concurso Melhores Receitas da Alimentação Escolar (BRASIL, 2015; FNDE, 2017).

O programa foi exibido pelo canal de televisão TV Escola e disponibilizado também no canal do YouTube sob o comando do ator Eri Johnson. Foram treze episódios, sendo que, em cada um, uma profissional deixava o programa e outra ganhava um prêmio no valor de um mil reais, muito semelhantes aos diversos produtos televisivos de competição culinária que preenchem as grades das TVs brasileiras.

Ações como os concursos e o reality show são importantes para darem visibilidade ao trabalho das merendeiras. Isso pode ajudar na valorização do seu papel. Porém acreditamos que esse tipo de ação pode também destacar o seu papel de cozinheira. Essas ações focam a preparação de receitas saborosas e saudáveis que é uma função extremamente importante da merendeira. Mas não dão destaque para o seu papel como sujeito integrante da escola enquanto educador.

Além disso, é necessário avaliar o alcance desse tipo de ação e se realmente desperta o interesse das merendeiras e do público em geral.

Para entender o impacto deste programa na vida das merendeiras, tanto das participantes quanto das não participantes, é necessário realizar estudos e pesquisas. Importante entender se há também algum impacto não só na vida das merendeiras, mas no olhar daqueles que podem interferir no seu trabalho, melhorando sua qualidade de vida ou fortalecendo sua profissão, além, é óbvio, de questionar o alcance de uma produção dessa natureza em um canal de baixíssima audiência como a TV Escola.

O que podemos, sem dúvida afirmar é que diferente dos dispositivos legais analisados até aqui, o recurso à identidade se faz presente, trabalha-se com o modo como os sujeitos produzem sua identificação temporária a um grupo, as merendeiras, faz-se alusão à produção da produção de seu imaginário como personagem importante na comunidade escolar, não são somente merendeiras, mas supermerendeiras, numa evidente produção de uma linguagem de empoderamento social (HALL, 2009; CASTORIADIS, 1982; BERTH, 2019). 


\section{Jornada de Educação Alimentar e Nutricional ${ }^{8}$}

Visando fortalecer a EAN no ambiente escolar e a inclusão da temática no processo de ensino e aprendizagem, a Coordenação Geral do PNAE tem implementado algumas iniciativas que envolvem diversos sujeitos do Programa. Uma das ações é a Jornada de Educação Alimentar e Nutricional que ocorre anualmente desde 2017. A Jornada consiste na seleção, divulgação e publicação das ações de EAN executadas nas escolas públicas de educação infantil e ensino fundamental, incentivando o debate e a prática no ambiente escolar e dar visibilidade àquelas já desenvolvidas nas escolas públicas.

A Jornada suscita o propósito pedagógico de chamar a atenção e debater, de forma estimulante e criativa sobre as temáticas da alimentação saudável, prevenção da obesidade e cultura alimentar. Cada edição da Jornada aconteceu ao longo do ano letivo, em etapas, cada uma com um tema diferente para o desenvolvimento de uma ação.

Neste momento pretendemos trazer uma análise do tema "Merendeira como agente transformadora da alimentação escolar" que foi trabalhado em 2019, na terceira edição da Jornada.

Para cada tema proposto na Jornada, materiais foram disponibilizados aos participantes para subsidiá-los no planejamento e na execução de uma atividade de EAN. A equipe da Coordenação do PNAE responsável pela Jornada gravou vídeos com especialistas no tema, disponibilizou livros, legislação, manuais e cartilhas e qualquer material que pudesse servir de apoio ao participante.

Foram encaminhados pelos participantes 520 relatos com fotos de atividades de EAN realizados pelas escolas com foco nas merendeiras. Destes, foram selecionados cinco para comporem a publicação Melhores Relatos da Educação Infantil e Ensino Fundamental I e II (BRASIL, 2020c).

Os relatos selecionados descrevem as atividades realizadas pelas escolas tais como: apresentação de receitas ancestrais reproduzidas pelas merendeiras e que são servidas na alimentação escolar; ações para conhecer a merendeira, já que (...) "a maioria dos educandos não sabia o nome da merendeira, se referindo a ela como a "tia do lanche" (BRASIL, 2020b, p. 33), homenagens para as merendeiras como preparação de lanches feitos pelos alunos, declamação de poesias, entrega de cartas de agradecimento e exposição de cartazes ressaltando a importância da merendeira. Também foram feitos jogos lúdicos entre merendeiras e alunos. Outro relato descreveu a realização de entrevistas com as merendeiras e após confeccionaram um livro sobre a biografia de uma delas.

Após a leitura dos relatos é possível verificar que essas atividades valorizam as merendeiras, dando um papel de destaque para a sua atuação tanto na preparação de uma alimentação saudável quanto na função de educadora.

Todas as atividades envolveram a comunidade escolar com a participação das famílias dos estudantes, professores, direção da escola, criando possibilidades de reconhecimento e valorização da merendeira. Ao colocar a merendeira como protagonista de atividades pedagógicas, contribui-se com a conscientização e valorização do seu papel enquanto educadora tanto para si quanto para os demais membros da comunidade escolar.

Ações como as propostas pela Jornada de EAN criam espaços potentes de reflexão quanto ao papel das merendeiras nas escolas públicas, podendo contribuir para a sua valorização.

Em um estudo realizado por Lourenção (2019) em Centros Municipais de Educação Infantil do município de Lavras, Minas Gerais, utilizou-se a Jornada de EAN como

\footnotetext{
${ }^{8}$ Importante esclarecer que uma das autoras deste trabalho atua diretamente no planejamento e na execução da Jornada de EAN, acompanhando este projeto desde o início de sua implantação. Então, a análise deste item vem permeada com o olhar de uma pessoa que está totalmente envolvida neste projeto.
} 
um dos módulos da intervenção educativa, a fim de qualificar diretoras, coordenadoras pedagógicas, professoras e auxiliares de serviços gerais. Concluiu-se que o programa de intervenção alimentar e nutricional proposto foi eficaz para a melhoria do conhecimento sobre alimentação e nutrição das educadoras.

Para que essas ações sejam efetivas, devem ser propostas e trabalhadas de forma contínua pelo FNDE, incentivando as escolas a participarem e desenvolveram atividades de EAN com toda a comunidade escolar. É necessário que haja também iniciativas que contribuam para a adesão de um maior número de escolas participantes, fortalecendo a EAN no ambiente escolar e contribuindo para a valorização das merendeiras.

\section{Quarta capa dos livros didáticos}

Desde 2016, as capas dos livros distribuídos pelo PNLD contêm ilustrações e mensagens que promovem a alimentação adequada e saudável. Buscando despertar o interesse e gerar reflexão com a proposta da inclusão da EAN nas escolas cada quarta capa de cada componente curricular aborda um tema mobilizador específico. A intenção é que cada tema possibilite gerar diálogos entre a comunidade escolar. Propomos, neste item do artigo, verificar se algum tema vinculado ao papel da merendeira já foi trabalhado em alguma capa.

As ilustrações e mensagens contidas nas capas dos livros distribuídos pelos PNLDs de 2016 a 2020 tratam de várias temáticas da educação alimentar e nutricional que vão desde cultura alimentar, sistema alimentar, hábitos alimentares saudáveis até outras questões que envolvem relações humanas e sustentabilidade.

Melgaço (2021), ao pesquisar as questões ambientais entrelaçadas com a alimentação adequada e saudável nas quartas capas dos livros didáticos distribuídos pelo PNLD 2018 - Ensino Médio verificou que os temas abordados nas capas propiciam espaços para reflexões e discussões de temas da Educação Ambiental e sustentabilidade tais como relações de produção, consumo e crise ambiental, identidade de gênero, relações de pertencimento com a natureza e sociedade, dentre outros. Para a autora, as mensagens contidas nas quartas capas dos livros didáticos ajudam a construir um espaço dialógico entre temas que são fundamentais para a formação dos escolares, possibilitando uma educação democrática e libertadora.

Ao analisar aspectos que permeiam o PNLD, Di Giorgi et al. (2014) situaram o livro didático como elemento importante na formação e ampliação do capital cultural do aluno e de forma estendida à sua família, especialmente aos escolares que pertencem às camadas mais desfavorecidas da sociedade e que podem ter um acesso prejudicado a livros. Além disso, os autores consideram que os livros didáticos se constituem um excelente recurso didático e pedagógico para os professores.

Greenwood e Fonseca (2016) descreveram como a EAN se constitui dentro do livro didático da Educação Básica, visualizando espaços e caminhos que possibilitam a sua otimização. Os autores indicam que os espaços de produção e utilização dos livros didáticos como as instâncias governamentais, editoras e escolas públicas contribuem potencialmente para que o aluno da escola pública tenha acesso a EAN. Deve haver diálogo e interação para que a EAN presente nos livros seja otimizada. Os livros podem oferecer questionamentos que instiguem a discussão sobre a alimentação escolar, facilitando e fortalecendo o processo educativo em alimentação e nutrição dentro da escola local.

Considerando a dimensão do PNLD e a sua importância para a formação dos escolares, o livro didático pode ser um instrumento importante para a promoção da alimentação adequada e saudável e para bons hábitos de vida. O espaço proporcionado pelas quartas capas para a geração de reflexões sobre essas temáticas tem se constituído como uma importante ferramenta de educação alimentar e nutricional. 
Esse espaço pode ser estratégico para se trabalhar a importância da merendeira para o PNAE, destacando o seu papel estratégico como educadora. Ainda não foi feita uma capa contendo uma mensagem específica sobre as merendeiras. Na capa "É gostoso comer com os amigos na escola" distribuída por meio do PNLD 2019 para os anos iniciais do ensino fundamental há a figura de duas merendeiras, uma servindo as crianças no refeitório e outra dentro da cozinha observando. Apesar delas apareceram nesta ilustração, o tema da capa propicia a reflexão sobre comer em companhia e não tem como temática principal o papel ou a importância da merendeira na escola.

A inclusão da temática que envolve a merendeira na quarta capa do livro didático pode ser então uma boa estratégia para se debater a importância dessa profissional para o PNAE e para gerar reflexões sobre o seu papel para e na comunidade escolar.

\section{Questionário de Monitoramento do PNAE}

A Coordenação Geral do Programa Nacional de Alimentação Escolar (CGPAE) do FNDE possui, em sua estrutura organizacional, uma coordenação específica de monitoramento e avaliação do Programa. Segundo a Resolução CD/FNDE nº 6/2020, o monitoramento do PNAE tem periodicidade permanente e visa corrigir possíveis distorções, aprimorar a gestão e subsidiar a sua avaliação por meio de levantamento de dados, análise e sistematização de informações e verificação da execução do Programa (BRASIL, 2020a).

Esta coordenação verifica a conformidade da execução do PNAE in loco e à distância por meio de questionários, entrevistas e observações, levando em consideração a legislação vigente e os seguintes aspectos: financeiro, compras da agricultura familiar, controle social e segurança alimentar e nutricional (BRASIL, 2015).

Durante a visita de monitoramento, é aplicado um questionário com as merendeiras composto por treze perguntas conforme descrição abaixo:

QUADRO 4 - Descrição das perguntas que compõem o monitoramento do PNAE feito pelo FNDE:

\begin{tabular}{|c|}
\hline Perguntas \\
\hline Dispõem de plano de carreira e remuneração? \\
\hline $\begin{array}{l}\text { Consideram que as condições de trabalho (materiais, mobiliário, equipamentos, ambiente e organização) são } \\
\text { adequadas, ou seja, proporcionam conforto, segurança e desempenho eficiente? }\end{array}$ \\
\hline A Prefeitura (ou Governo do Estado) solicita a realização de exames para controle da saúde periodicamente? \\
\hline O(s) Atestado(s) de Saúde Ocupacional (ASOs) está/estão disponível/disponíveis na escola? \\
\hline Considera $(\mathrm{m})$ que a quantidade de manipuladores é suficiente? \\
\hline Segue $(\mathrm{m})$ o Manual de Boas Práticas (MBP)? \\
\hline Segue $(\mathrm{m})$ os Procedimentos Operacionais Padronizados (POPs)? \\
\hline Segue $(\mathrm{m})$ as Fichas Técnicas de Preparação (FTPs)? \\
\hline $\begin{array}{l}\text { Usa(m) o(s) cabelo(s) preso(s) e protegido(s) por rede(s) e/ou touca(s) como Equipamento(s) de Proteção } \\
\text { Individual (EPI(s))? }\end{array}$ \\
\hline $\begin{array}{l}\text { Conta(m) com uniforme(s) (luvas, avental(is) e botas ou sapatos fechados) como Equipamento(s) de } \\
\text { Proteção Individual (EPI(s))? }\end{array}$ \\
\hline $\begin{array}{l}\text { Lava }(\mathrm{m}) \text { cuidadosamente as mãos, praticando a antissepsia e demais hábitos de higiene antes e após a } \\
\text { manipulação? }\end{array}$ \\
\hline Retira(m) os adornos (brincos, pulseiras, alianças, relógios, colares, anéis ou piercings)? \\
\hline Recebe $(\mathrm{m})$ capacitação periódica em higiene e saúde? \\
\hline
\end{tabular}

As perguntas estão relacionadas às legislações que envolvem a execução do PNAE e as normas que regulamentam a profissão de manipuladores de alimentos. Desta forma, as perguntas querem verificar se estão sendo cumpridos os seguintes normativos: Parecer 9/2010 e a Resolução N. ${ }^{\circ}$ 5/2010 do Conselho Nacional de Educação/Câmara de Educação Básica (CNE/CEB), que fixa as Diretrizes Nacionais para os Planos de Carreira e 
Remuneração dos Funcionários da Educação Básica Pública (BRASIL, 2010a, 2010b); RDC ANVISA n. ${ }^{\circ}$ 216/2004 (BRASIL, 2004); Norma Regulamentadora NR 7 (Exames Médicos) do Programa de Controle Médico de Saúde Ocupacional, publicada pela Portaria do Ministério do Trabalho n. ${ }^{\circ} 3.214 / 1978$ (BRASIL, 1978); Portaria SVS/MS no 326/1997, 5 ("Documentação") do Anexo II da RDC ANVISA no 275/2002 (BRASIL, 1997, 2002); Resolução/CD/FNDE n. ${ }^{\circ}$ 6/2020 (BRASIL, 2020a).

Considerando que a alimentação adequada e saudável é um direito fundamental do ser humano (BRASIL, 1988), o PNAE busca garantir a segurança alimentar e nutricional dos estudantes nas escolas. A garantia da segurança alimentar e nutricional dos escolares depende de uma série de procedimentos que devem ser rigorosamente seguidos durante todo o processo que envolve a manipulação dos alimentos. Esses procedimentos estão descritos em uma série de regulamentos e legislações e cabe ao FNDE estar atento e monitorar o cumprimento destas normas. As questões nutricionais e higiênico-sanitárias da alimentação escolar estão intrinsecamente envolvidas com as merendeiras, que devem utilizar técnicas de preparo dos alimentos adequadas, zelando pela saúde dos escolares. A execução da alimentação escolar deve ser avaliada e monitorada pela equipe do PNAE/ FNDE, assim como pelos nutricionistas do Programa e pelas entidades executoras.

Percebe-se a preocupação com as questões higiênico-sanitárias da alimentação escolar nas treze perguntas voltadas paras as merendeiras que constam no monitoramento. Porém, não há nenhuma pergunta direcionada a função da merendeira enquanto educadora. Este pode ser um indicativo da invisibilização desse papel da merendeira pelo Programa.

\section{CONSIDERAÇÕES FINAIS}

A partir da análise dos documentos e projetos do PNAE que envolvem a merendeira, podemos perceber que o Programa possui arcabouço legal e espaço para fortalecer e valorizar essa importante profissional promotora de alimentação saudável e adequada no ambiente escolar, mas, que, de muitas formas, reforça o processo de invisibilização das merendeiras.

Para Recine (2017) as ações de educação alimentar e nutricional no cotidiano escolares têm sido fomentadas a partir de iniciativas do PNAE como a Jornada de Educação Alimentar e Nutricional e mensagens sobre os temas de alimentação e nutrição nas quartas capas dos livros didáticos distribuídos pelo PNLD.

Porém, no que concerne às merendeiras, a análise sugere que apesar de parecer haver uma predisposição e vontade da Coordenação do PNAE em reconhecer e valorizar as merendeiras, as ações ficam mais voltadas para as tentativas de comunicação com o grupo (Reality Shows, Concursos) que para a inscrição no discurso oficial, muito menos focado na representação e mais num certo senso comum da representatividade. As merendeiras estão de alguma forma representadas em algumas ações como no concurso "Melhores Receitas da Alimentação Escolar" e no reality Show Super Merendeiras. A presença das merendeiras nesses projetos pode significar que a sua ausência foi suprida, mas a sua presença continua problemática quando no discurso oficial, ora ficam de fora ou ora são tratadas de forma despersonalizada e muito distante do arranjo identitário que as situa socialmente como grupo, merendeiras.

A opção por manipuladora de alimentos no trato frio dos dispositivos legais e de merendeira quando se pretende uma aproximação com esta profissional revela, no mínimo, um desconhecimento por parte de quem está elaborando esses documentos da importância de se ver como parte de um grupo. Outros sujeitos da educação, como os professores não são conhecidos de outra forma, na lei e na comunicação são tratados da mesma forma. 
A discussão de representação e representatividade pode ser levada para dentro do PNAE. A ausência de sujeitos sociais nos documentos e projetos do PNAE deve ser criticada, especialmente quando o contexto dessas pessoas está atrelado a minoria em representação. Ou seja, o grupo social é constituído por mulheres, negras e de baixa renda. Apesar desse estrato social se constituir em um grupo populacional gigante no Brasil é a minoria social em termos de representação.

O processo de terceirização com a extinção do cargo público de merendeira configura a sua desvalorização (Pinho e Martínez, 2016). As merendeiras são identificadas nos contratos terceirizados como manipuladoras de alimentos, e o fato de não as identificar como merendeiras colabora com a crescente diminuição da identidade destas profissionais com o cargo. Os autores do estudo indicam que apesar de não serem identificadas como "merendeiras", ela é assim reconhecida por todos os outros agentes escolares, bem como em outros estudos utilizados como referência.

Apesar da nomenclatura "manipulador de alimentos" soar para alguns um tanto mais profissional que merendeira, é importante pensar que a definição de manipulador de alimentos é restrita a uma função técnica, operacional e higienista. A merendeira não é apenas cozinheira ou manipuladora de alimentos, pois sua função vai além de preparar as refeições. Ela é também educadora, formando o elo entre o estudante e o alimento. Ao servir as refeições, a merendeira pode incentivar o estudante a se alimentar e orientá-lo na formação de bons hábitos alimentares.

Pensar na nomenclatura dessa profissional nos leva a refletir sobre as funções que estão destinadas ou que influenciam o seu fazer na escola e no Programa.

A representatividade tem papel central na formação de identidades e subjetividades. Desta forma, quando o PNAE representa a merendeira em projetos ou documentos como cozinheira ou como manipuladora de alimentos, excluindo a pluralidade do seu papel enquanto educadora, reforça seu estereótipo voltado apenas para o preparo do alimento e a higienização das áreas físicas. Isso contribui para o seu desprestígio social e a consolidação da sua função enquanto sujeito subalterno. Ao reforçar estereótipos e a discriminação, pode invisibilizar seus saberes.

A presença de documentos ou ações que fortaleçam o papel de educadora da merendeira também pode contribuir com a valorização dessa profissão e de melhores condições de vida e de trabalho. Existe uma preocupação quanto à prática do controle higiênico sanitário da merendeira enquanto manipuladora de alimentos. Mas são poucas as ações que reforçam o seu papel de educadora.

O PNAE possui espaços que se explorados podem ser potentes para gerar a reflexão dos papéis das merendeiras e o fortalecimento da educação alimentar e nutricional. Capacitações ou cursos coordenados pelos CECANEs, continuidade de ações vinculadas com a Jornada de EAN, inserção de mensagens e ilustrações nas quartas capas dos livros didáticos, elaboração e divulgação de notas técnicas, inserção do papel de educadora da merendeira em legislação, avaliação e monitoramento desse papel são alguns desses espaços que podem contribuir para a representatividade das merendeiras no PNAE.

O incentivo à inclusão de temáticas da promoção da alimentação saudável e adequada, ao trabalho inter e transdisciplinar entre docentes e demais funcionários da escola e do envolvimento dos demais sujeitos do PNAE no projeto político pedagógico das escolas, o reconhecimento do papel da merendeira enquanto educadora, são iniciativas que podem ser despertadas e propagadas por meio de ações do PNAE.

Insistimos em chamarmos atenção para a produção da subalternidade da merendeira o fazemos por entendermos que esse processo não se constitui e nem desaparece de um dia para o outro. É necessário dizer, dizer de novo mais uma vez e sempre para sermos escutados, de outra forma a linguagem que naturaliza a subalternidade, que vê essas mulheres como parte da paisagem da cantina da escola jamais encontrará o contraditório, a crítica e 
seguirá reproduzindo sua gramática excludente que se materializa na exclusão dos sujeitos. Se ainda hoje precisamos lembrar aos membros dessa sociedade que racismo existe, as discriminações baseadas em classe social (hooks, 2000), o classismo, ainda precisa adentrar mais fortemente o debate, podemos começar por chamar as mulheres que trabalham nas cozinhas das escolas por merendeiras, que é como elas se reconhecem e são reconhecidas.

Contribuição dos autores: Mariana Belloni Melgaço é a autora da dissertação de mestrado que deu origem a este artigo. Fez a revisão deste trabalho. Rodrigo Matos-de-Souza é o orientador do mestrado. Ambos participaram fisicamente e intelectualmente da escrita deste manuscrito.

Conflito de interesses: Nada declarado pelos autores.

\section{REFERÊNCIAS}

ARAÚJO, Aillen Leite; et. al. O Impacto da Educação Alimentar e Nutricional na Prevenção do Excesso de Peso em Escolares: Uma revisão Bibliográfica. Revista Brasileira de Obesidade, Nutrição e Emagrecimento. v.11, n. 62, p.94-105. 2017. Disponível em:

http://www.rbone.com.br/index.php/rbone/article/view/494. Acesso em: 06 abr. 2021.

BERTH, Joyce. Empoderamento. São Paulo: Editora Jandaíra, 2019.

BORSOI, Aline Tecchio; TEO, Carla Roseane Paz Arruda; MUSSIO, Bruna Roniza. Educação alimentar e nutricional no ambiente escolar: uma revisão integrativa. Revista IberoAmericana de Estudos em Educação, Araraquara, v. 11, n. 3, p. 1441-1460, 2016. https://doi.org/10.21723/riaee.v11.n3.7413.

BRASIL. Presidência da República. Lei n 11.947, de 16 de junbo de 2009. Dispõe sobre o atendimento da alimentação escolar e do Programa Dinheiro Direto na Escola aos alunos da educação básica; altera as Leis nos 10.880, de 9 de junho de 2004, 11.273, de 6 de fevereiro de 2006, 11.507, de 20 de julho de 2007; revoga dispositivos da Medida Provisória no 2.178-36, de 24 de agosto de 2001, e a Lei no 8.913, de 12 de julho de 1994; e dá outras providências. Brasília, DF: Presidência da República, 2009.

Fundo Nacional de Desenvolvimento da Educação (FNDE). Monitoramento e

Avaliação do Programa Nacional de Alimentação Escolar, 2015. Disponível em:

https://www.gov.br/fnde/pt-br/acesso-a-informacao/acoes-eprogramas/programas/pnae/pnae-apresentacoes Acesso em: 07 maio 2021.

Ministério da Educação. Fundo Nacional de Desenvolvimento da Educação.

Resolução $n^{\circ} 6$ de 08 de maio de 2020. Dispõe sobre o atendimento da alimentação escolar aos alunos da educação básica no Programa Nacional de Alimentação Escolar - PNAE. Brasília, DF: MEC/FNDE, 2020a.

Ministério da Educação. Fundo Nacional de Desenvolvimento da Educação. Resolução $n^{\circ}$ 20, de 02 de dezembro de 2020. Altera a Resolução/CD/FNDE no 6, de 8 de maio de 2020, que dispõe sobre o atendimento da alimentação escolar aos alunos da educação básica no âmbito do Programa Nacional de Alimentação Escolar - PNAE. Brasília, DF: MEC/FNDE, 2020b. 
. Ministério do Desenvolvimento Social e Combate à Fome. Secretaria Nacional de Segurança Alimentar e Nutricional. Marco de referência de educaşão alimentar e nutricional para as politicas públicas. Brasília, DF: MDS, 2012.

Ministério da Educação. Fundo Nacional de Desenvolvimento da Educação. Material orientativo para formação de manipuladores de alimentos que atuam na alimentação escolar. Elaboração: Centro Colaborador Alimentação e Nutrição do Escolar da Universidade Federal do Rio Grande do Sul. Brasília, DF: Ministério da Educação, 2014.

Ministério da Educação. Conselho Nacional de Educação. Câmara de Educação Básica. Parecer 9/2010. Aprecia a Indicação CNE/CEB no 3/2009, que propõe a elaboração de Diretrizes Nacionais para os Planos de Carreira e Remuneração dos Funcionários da Educação Básica Pública. Brasília, DF: MEC, 2010a.

Ministério da Educação. Conselho Nacional de Educação. Câmara de Educação Básica. Resolução n216 5 , de 3 de agosto de 2010. Fixa as Diretrizes Nacionais para os Planos de Carreira e Remuneração dos Funcionários da Educação Básica pública. Brasília, DF: $\mathrm{MEC} / \mathrm{CNE} / \mathrm{CEB}, 2010 \mathrm{~b}$.

Ministério da Educação; Ministério da Saúde. Portaria Interministerial No 1.010, de 08 de maio de 2006. Institui as diretrizes para a Promoção da Alimentação Saudável nas Escolas de educação infantil, fundamental e nível médio das redes públicas e privadas, em âmbito nacional. Brasília, DF: MEC/ MS, 2006.

. Ministério da Educação. Fundo Nacional de Desenvolvimento da educação. Jornada de educação alimentar e nutricional: Melhores Relatos da educação Infantil e Ensino Fundamental I e II / Programa Nacional de Alimentação Escolar, 3. ed. Brasília, DF: FNDE, 2020c.

Ministério da Saúde. Agência Nacional de Vigilância Sanitária. Resolução No 216, de 15 de setembro de 2004. Dispõe sobre Regulamento Técnico de Boas Práticas para Serviços de Alimentação. Brasília, DF: MS/ANVISA, 2004.

Ministério da Saúde. Agência Nacional de Vigilância Sanitária. Resolução - RDC $n^{\circ}$ 275, de 21 de outubro de 2002. Dispõe sobre o Regulamento Técnico de Procedimentos Operacionais Padronizados aplicados aos Estabelecimentos Produtores/Industrializadores de Alimentos e a Lista de Verificação das Boas Práticas de Fabricação em Estabelecimentos Produtores/Industrializadores de Alimentos. Brasília, DF: MS/ANVISA, 2002.

- Ministério da Saúde. Secretaria de Vigilância Sanitária. Portaria n 326, de 30 de julho de 1997. Aprova o Regulamento Técnico "Condições Higiênicos-Sanitárias e de Boas Práticas de Fabricação para Estabelecimentos Produtores/Industrializadores de Alimentos. Brasília, DF: MS/ANVISA, 1997.

- Ministério do Trabalho. Portaria n. ${ }^{\circ} 3.214,08$ de junho de 1978. Aprova as Normas Regulamentadoras - NR - do Capítulo V, Título II, da Consolidação das Leis do Trabalho, relativas à Segurança e Medicina do Trabalho. Brasília, DF: MT, 1978.

Presidência da República. Lei ñ 11.346, de 15 de setembro de 2006. Cria o Sistema Nacional de Segurança Alimentar e Nutricional - SISAN com vistas em assegurar o direito 
humano à alimentação adequada e dá outras providências. Brasília, DF: Presidência da República, 2006.

Presidência da República. Lei n 13.666, de 16 de maio de 2018. Altera a Lei no 9.394, de 20 de dezembro de 1996 (Lei de Diretrizes e Bases da Educação Nacional), para incluir o tema transversal da educação alimentar e nutricional no currículo escolar. Brasília, DF: Presidência da República, 2018.

Presidência da República Lei no 9.394, de 20 de dezembro de 1996. Estabelece as diretrizes e bases da educação nacional. Brasília, DF: Presidência da República, 1996.

Presidência da República. Constituição da República Federativa do Brasil de 1988. Brasília, DF: Presidência da República, 1988.

Presidência da República. Decreto n 37.106, de 31 de março de 1955. Institui a Companhia da Merenda Escolar. Brasília, DF: Presidência da República, 1955.

Edital de 9 de setembro de 2015. Concurso "Melhores Receitas da Alimentação Escolar". Diário Oficial da União: seção 3, Brasília, DF, no 173, p. 39, 10 set. 2015.

CAMOZZI, Aída Bruna Quilici; MONEGO, Estelamaris Tronco; MENEZES, Ida Helena Carvalho Francescantonio; SILVA, Priscila Olin. Promoção da Alimentação Saudável na Escola: realidade ou utopia? Cad. saúde colet., Rio de Janeiro, v. 23, n. 1, p. 32-37, 2015. http://dx.doi.org/10.1590/1414-462X201500010006.

CASAGRANDE, Solange; CANCELIER, Janete Webler; BELING, Helena Maria. Programa Nacional De Alimentação Escolar (PNAE): Contribuição na Alimentação Saudável Escolar e Promoção da Agricultura Familiar. Revista Brasileira de Desenvolvimento, Curitiba, v.7, n.3, p.25835-25849, 2021. https://doi.org/10.34117/bjdv7n3-337.

CASEMIRO, Juliana Pereira; FONSECA, Alexandre Brasil C. da; MACHADO, Elaine Cristina da Silva; PERES, Solange Carvalho. Impasses, desafios e as interfaces da educação alimentar e nutricional como processo de participação popular. Trab. educ. saúde, Rio de Janeiro, v. 13, n. 2, p. 493-514, 2015. http://dx.doi.org/10.1590/1981-7746-sip00051.

CASTORIADIS, Cosnelius, A Instituição Imaginária da Sociedade. Rio de Janeiro: Paz e Terra, 1982.

CHARTIER, Roger. Formas e Sentido. Cultura escrita: entre distinção e apropriação. Campinas, SP: Mercado de Letras, 2003.

CHAVES, Lorena Gonçalves. Formação de Merendeiras na Perspectiva da Promoção da Alimentação Saudável na Escola: as Capacitações no Âmbito dos Centros Colaboradores em Alimentação e Nutrição do Escolar. Dissertação (Mestrado em Ciências da Saúde). São Paulo: Universidade Federal de São Paulo, 2011. Disponível em: http://repositorio.unifesp.br/handle/11600/21944 Acesso em: 28 mar. 2021.

COLLINS, Patricia Hill. Pensamento Feminista Negro. São Paulo: Boitempo, 2019.

CONSELHO FEDERAL DE NUTRICIONISTAS (CFN). Resolução CFN No 465, de 23 de agosto de 2010. Dispõe sobre as atribuições do Nutricionista, estabelece parâmetros 
numéricos mínimos de referência no âmbito do Programa de Alimentação Escolar (PAE) e dá outras providências. Brasília, DF: CFN, 2010.

DI GIORGI, Cristiano Amaral Garboggini et al. Uma proposta de aperfeiçoamento do PNLD como política pública: o livro didático como capital cultural do aluno/família. Ensaio: aval.pol.públ.Educ., Rio de Janeiro, v. 22, n. 85, p.1027-1056, 2014. http://dx.doi.org/10.1590/S0104-40362014000400008

FERNANDES, Ana Gabriela de Souza; FONSECA, Alexandre Brasil Carvalho da; SILVA, Adilson Aderito da. Alimentação escolar como espaço para educação em saúde: percepção das merendeiras do município do Rio de Janeiro, Brasil. Ciênc. saúde coletiva, Rio de Janeiro, v. 19, n. 1, 2014. http://dx.doi.org/10.1590/1413-81232014191.1711.

FUNDO NACIONAL DE DESENVOLVIMENTO DA EDUCAÇÃO (FNDE). Notas Técnicas | Pareceres | Relatórios [internet].18/02/2021. https://www.gov.br/fnde/pt$\mathrm{br} /$ acesso-a-informacao/acoes-eprogramas/programas/pnae/pnaenotastecnicaspareceresrelatorios . Acesso em: 14 de mar. 2021.

. EDITAL No003/2017. Concurso Melhores Receitas da Alimentação Escolar - $2^{\mathrm{a}}$ Edição. Disponível em: https://www.gov.br/fnde/pt-br/acesso-a-informacao/acoes-eprogramas/programas/pnae/campanhas/pnae-concurso-melhores-receitas Acesso em: 14 de mar. 2021.

. Manual de apoio para atividades técnicas do nutricionista no âmbito do PNAE / Programa Nacional de Alimentação Escolar. Brasília: FNDE, 2018.

GREENWOOD, Suzana de Azevedo; FONSECA, Alexandre Brasil. Espaços e caminhos da educação alimentar e nutricional no livro didático. Ciência e Educação, Bauru, v. 22, n. 1, p. 201-218, 2016. http://dx.doi.org/10.1590/1516-731320160010013.

HALL, Stuart. Quem precisa da identidade. In: SILVA, Tomaz Tadeu (org.). Identidade e diferença: a perspectiva dos Estudos Culturais. Petrópolis, RJ: Vozes, 2009.

hooks, bell. Where we stand: class matters. New York \& London: Routledge, 2000.

JANUÁRIO, Ana Cláudia dos Santos et al. A cozinha como um espaço de trabalho feminino negro. In: MELO, Paula Balduíno de; COÊLHO, Jaqueline; FERREIRE, Larissa; SILVA, Diene Ellen Tavares. Descolonizar o feminismo: Brasília: IFB, 2019.

KILOMBA, Grada. Memórias da Plantação: episódios de racismo cotidiano. Rio de Janeiro: Cobogó, 2019.

KINCHELOE, Joe L.; BERRY, Kathleen S. Pesquisa em educação: Conceituando a bricolagem. Artmed, 2007.

KROTH, Darlan C.; GEREMIA, Daniela S.; MUSSIO, Bruna Roniza. Programa Nacional de Alimentação Escolar: uma política pública saudável. Ciência \& Saúde Coletiva [online]. v. 25, n. 10, pp. 4065-4076, 2020. https://doi.org/10.1590/1413-812320202510.31762018.

KUTZ, Nyvian Alexandre. Estado nutricional, qualidade de vida e a percepção das cozinheiras escolares de Carapicuíba sobre aspectos da sua atuação profissional. 2018. Dissertação (Mestrado em 
Nutrição Humana Aplicada). São Paulo: Universidade de São Paulo, 2018. doi:10.11606/D.89.2018.tde-18122018-173421.

LIMA, Rogério Mendes; CARVALHO, Elisa Costa de. Destinos traçados? Gênero, raça, precarização e resistência entre merendeiras do Rio de Janeiro. Revista da ABET, v. 15, n.1, 2016. Disponível em: https://periodicos.ufpb.br/ojs/index.php/abet/article/view/31263 Acesso em: 05 abr. 2021.

LOURENÇÃO, Luiz Felipe de Paiva. Avaliação nutricional de pré-escolares e a implementação de um programa educativo nutricional voltado aos servidores da educaşão infantil. 2019. Dissertação (Mestrado em Ciências da Saúde). Lavras: Universidade Federal de Lavras, 2019. Disponível em: http://repositorio.ufla.br/jspui/handle/1/34939. Acesso em: 05 abr. 2021.

MATOS-DE-SOUZA, Rodrigo et al. Migração e educação: Um estudo sobre a invisibilização do migrante nas políticas educacionais brasileiras e distrital. Arquivos Analíticos de Politicas Educativas, Vol. 29, 2021. https://doi.org/10.14507/epaa.29.5540.

MELGAÇO, Mariana Belloni. Educação Alimentar e Nutricional e Educação Ambiental: um espaço dialógico comum no Programa Nacional de Alimentação Escolar. In: Anais do Fórum Internacional de Pedagogia - FIPED (Edição Salamanca). Cajazeiras (PB) USAL, 2021. Disponível em: https://www.even3.com.br/anais/fipedsalamanca/284286-educacaoalimentar-e-nutricional-e-educacao-ambiental--um-espaco-dialogico-comum-no-programanacional-de-alimenta/ Acesso em: 22 de mar. 2021.

OTTONI, Isabela Cicaroni; OLIVEIRA, Bruno Miguel Paz Mendes de; BANDONI, Daniel Henrique. O Programa Nacional de Alimentação Escolar como promotor de ações de Educação Alimentar e Nutricional nas escolas do Brasil. Mundo saúde. São Paulo, v. 43, n. 2, p. 374-389, 2019. DOI: 10.15343/0104-7809.20194302374389.

PEDRAZA, Dixis Figueroa et al. Avaliação do Programa Nacional de Alimentação Escolar: revisão da literatura. Ciência \& Saúde Coletiva [online]. 2018, v. 23, n. 5, pp. 1551 1560, 2018. <https://doi.org/10.1590/1413-81232018235.17832016>.

PEIXINHO, Albaneide M. L. A trajetória do Programa Nacional de Alimentação Escolar no período de 2003- 2010: relato do gestor nacional. Ciência \& Saúde Coletiva, Rio de Janeiro, v. 18, n. 4, p. 909 - 916, 2013. http://dx.doi.org/10.1590/S1413 81232013000400002

PINHO, Francine N. L. Garcia; MARTÍNEZ, Silvia Alicia. Representações sociais da alimentação escolar: quem é a merendeira? In: XIII Encontro Nacional de História Oral, Universidade Federal do Rio Grande do Sul, 2016. Disponível em: http://www.historiaoral.org.br/resources/anais/13/1461618840 ARQUIVO textocompl eto-PINHO.pdf . Acesso em: 22 de mar. 2021.

POLLAN, Michael. Em defesa da comida - Um manifesto. Editora Intrínseca, São Paulo: 2008.

RECINE, Elisabetta. O Programa Nacional de Alimentação Escolar: o mundo se inspira, seremos capazes de manter os avanços? Cad. Saúde Pública, Rio de Janeiro, v. 33, n. 12, e 00087617, 2017. http://dx.doi.org/10.1590/0102-311x00087617.

SAID, Edward. W. Cultura e Política. São Paulo: Boitempo, 2012. 
SANTOS, Adriano M. dos. Revisão sistemática sobre educação alimentar e nutricional: sujeitos, saberes e práticas em diferentes cenários. Saúde.com, [S. l.], v. 11, n. 4, p. 425-442, 2016. Disponível em: https://periodicos2.uesb.br/index.php/rsc/article/view/387. Acesso em: 6 abr. 2021.

SANTOS, Ligia Amparo da Silva. Educação alimentar e nutricional no contexto da promoção de práticas alimentares saudáveis. Rev. Nutr., Campinas, v. 18, n. 5, p. 681 692, 2005. http://dx.doi.org/10.1590/S1415-52732005000500011.

SANTOS, Ligia Amparo da Silva. O fazer educação alimentar e nutricional: algumas contribuições para reflexão. Ciência e saúde coletiva, Rio de Janeiro, v. 17, n. 2, p. 455462, 2012. http://dx.doi.org/10.1590/S1413-81232012000200018.

SILVA, Simoni U. da; MONEGO, E. Tronco; SOUSA, Lucilene M. de; ALMEIDA, Géssica Mercia de. As ações de educação alimentar e nutricional e o nutricionista no âmbito do Programa Nacional de Alimentação Escolar. Ciênc. saúde coletiva, Rio de Janeiro, v. 23, n. 8, p. 2671-2681, 2018. http://dx.doi.org/10.1590/1413-81232018238.19642016.

SPIVAK, Gayatri Chakravorty. An Aesthetic Education in the Era of Globalization. Cambridge, MA: Harvard University Press, 2013a.

SPIVAK, Gayatri Chakravorty. En otras palabras, en otros mundos: ensayos sobre política cultural. Buenos Aires: Paidós, 2013b.

SPIVAK, Gayatri Chakravorty. Pode o subalterno falar? Belo Horizonte: Editora UFMG, 2010.

STANDING, Guy. O Precariado: a nova classe perigosa. Belo Horizonte, 2017.

TEO, Carla Rosane Paz Arruda; SABEDOT, Francielli Regina Boroski; SCHAFER, Elisângela. Merendeiras como agentes de educação em saúde da comunidade escolar: potencialidades e limites. Revista Espaço para a Saúde, Londrina, v. 11, n. 2, p. 11-20, 2010. https://doi.org/10.22421/15177130-2010v11n2p11.

VALENTE, Flavio Luiz Schieck. Rumo à Realização Plena do Direito Humano à Alimentação e à Nutrição Adequadas. Artigo originalmente publicado em inglês na Revista Development, v. 57, n. 2, p. 155-170, 2014. Traduzido para o português em maio de 2016 para a FIAN Brasil. Disponível em: https://fianbrasil.org.br/wpcontent/uploads/2017/02/Rumo- $\% \mathrm{C} 3 \% \mathrm{~A} 0$-realiza $\% \mathrm{C} 3 \% \mathrm{~A} 7 \% \mathrm{C} 3 \% \mathrm{~A} 30-$ plena-doDHANA Flavio-Valente.pdf Acesso em: 30 mar. 2021. 